\title{
PRINSIP KETIDAKPASTIAN HEISENBERG DALAM TINJAUAN KEMAJUAN PENGUKURAN KUANTUM DI ABAD 21
}

\author{
Jesi Pebralia* \\ Program Studi Fisika, Fakultas Sains dan Teknologi, Universitas Jambi, Jl. Jambi-Ma.Bulian Km.15, Muaro Jambi, 36122, Indonesia \\ *e-mail: jesipebralia@unja.ac.id
}

\begin{abstract}
ABSTRAK
Prinsip ketidakpastian Heisenberg merupakan fondasi dasar dari ilmu fisika kuantum yang menjadi ciri khas fisika kuantum dengan fisika klasik. Prinsip ketidakpastian Heisenberg memberikan batasan dimana tidak adanya hasil pengukuran mutlak dalam setiap pengukuran kuantum. Seiring dengan perkembangan instrumen pengukuran yang semakin canggih di abad 21, menghadirkan peluang munculnya modifikasi dari prinsip ketidakpastian Heisenberg dari bentuk umum formulasi yang telah ada. Penelitian ini bertujuan untuk memberikan gambaran peluang munculnya formulasi modifikasi prinsip ketidakpastian Heisenberg dan memberikan gambaran tahapan penurunan modifikasi bentuk formulasi prinsip ketidakpastian Heisenberg yang telah ditelaah oleh peneliti terdahulu. Metode penelitian yang digunakan adalah metode studi literatur yang bertujuan untuk mengetahui latar belakang dan teori-teori perkembangan prinsip ketidakpastian Heisenberg dan metode penurunan formulasi by hand yang bertujuan untuk mengetahui runtutan teknis dari modifikasi formulasi yang ada. Melalui penelitian ini, penulis berhasil mendapatkan adanya peluang munculnya modifikasi baru formulasi prinsip ketidakpastian Heisenberg.
\end{abstract}

Kata Kunci: Fisika Kuantum; Instrumen Pengukuran; Modifikasi Prinsip Ketidakpastian; Prinsip Ketidakpastian Heisenberg; Pengukuran Kuantum.

\section{ABSTRACT}

[Title: Heisenberg Uncertainty Principle in The Perspective of Advance Quantum Measurement in $21^{\text {st }}$ Century] The Heisenberg uncertainty principle is the basic foundation of quantum physics that characterizes quantum physics with classical physics. The Heisenberg uncertainty principle provides boundaries where there are no absolute measurement results in any quantum measurement. Along with the development of increasingly sophisticated measurement instruments in the 21st century, presents the opportunity for the emergence of modifications from the Heisenberg uncertainty principle from the general form of existing formulations. This study aims to provide an overview of the opportunities for Heisenberg uncertainty formulation and provide a description of the stages of the Heisenberg uncertainty formulation's uncertainty formulations that have been reviewed by previous researchers. The research method used is the method of literature study that aims to find out the background and theories of the development of Heisenberg's uncertainty principle and to explain the formulation directly which aims to determine the technical sequence of modifications to the existing formulation. Through this research, the authors managed to get an opportunity for the emergence of new modifications to the Heisenberg uncertainty principle formulation.

Keywords: Quantum Physics; Instrument of Measurement; Modification of Uncertainty Principle; Heisenberg Uncertainty Principle; Quantum Measurement.

\section{PENDAHULUAN}

Teori kuantum merupakan teori yang bersifat indeterministik. Pada setiap hasil pengamatannya tidak dapat menghasilkan nilai yang pasti. Sebagai contoh, pengamatan untuk menentukan posisi dan momentum elektron. Dalam teori kuantum, selalu terdapat ketidakpastian dalam pengamatan observabel kuantum (Zettili, 2001). Ketidakpastian tersebut bukanlah disebabkan oleh ketidaktelitian peratalam yang digunakan untuk melakukan pengukuran, melainkan ketidakpastian tersebut merupakan sifat alamiah dari objek-objek berukuran mikroskopik .
Prinsip ketidakpastian dalam teori fisika kuantum merupakan sifat alami yang dimiliki oleh objek berukuran mikroskopis yang membedakan dunia kuantum dengan objek kasat mata yang dijelaskan oleh teori fisika klasik. Objek kuantum direpresentasikan menggunakan fungsi gelombang dan peluang menemukan partikel dalam suatu fungsi gelombang dapat dicari menggunakan amplitudo probabilitas (interpretasi Born) (Griffiths, 2018). Berdasarkan teori kuantum, untuk melakukan pengamatan terhadap objek mikroskopis seperti elektron pasti akan merusak fungsi gelombang elektron tersebut (merusak sistem) dan fungsi 
gelombang secara alamiah akan berpindah ke keadaan pengukuran yang diinginkan.

Formulasi dasar yang menyatakan tentang adanya ketidakpastian kuantum dikemukakan oleh Heisenberg tahun 1928 yang menyatakan bahwa dalam pengukuran dua buah observabel kuantum yang dilakukan secara bersamaan misalnya posisi dan momentum, maka tidak mungkin untuk mendapatkan hasil pengukuran kedua observabel dengan ketelitian sempurna (Heisenberg, 1927). Konsekuensi dari prinsip tersebut ialah apabila hasil pengukuran posisi elektron dapat diketahui dengan pasti, maka kita tidak dapat memperoleh hasil pengukuran momentum dengan ketelitian yang tinggi.

Keunikan yang ditunjukkan oleh objek kuantum telah menarik minat banyak peneliti untuk mempelajari lebih mendalam fenomena-fenomena dan hukum fisika yang melingkupinya. Salah satunya ialah perkembangan formulasi prinsip ketidakpastian kuantum yang dikemukakan oleh Heisenberg. Pada tahun 2012, Rozeema dkk., melalui eksperimen tiga keadaan mengkonfirmasi peluang modifikasi prinsip ketidakpastian yang dikemukakan oleh Ozawa (2003). Modifikasi prinsip ketidakpastian tersebut muncul dengan mempertimbangkan adaya dua observabel kuantum yang muncul pada saat pengukuran berlangsung yaitu observabel kesalahan (error) dan observabel gangguan (disturbance).

Peluang munculnya modifikasi prinsip ketidakpastian juga tidak terlepas dari adanya perkembangan instrumen pengukuran yang semakin canggih, baik pengukuran secara langsung maupun tidak langsung. Beberapa penelitian sebelumnya yang telah dilakukan dalam memanfaatkan perkembangan teknologi di abad 21 misalnya pengukuran menggunakan bantuan software tertentu (Pebralia, 2019), pengukuran menggunakan sensor [(Rozeema, dkk. 2015), (Putu, dkk., 2015)], dan lain sebagainya.

\section{METODE}

Metode penelitian yang digunakan adalah metode studi literatur yang bertujuan untuk mengetahui latar belakang dan teori-teori yang mendukung perkembangan prinsip ketidakpastian Heisenberg dan metode penurunan formulasi by hand yang bertujuan untuk mengetahui runtutan teknis dari modifikasi formulasi prinsip ketidakpastian Heisenberg sebagaimana penelitianpenelitian terdahulu yang telah dilakukan oleh peneliti (Pebralia, dkk., 2019).

\section{HASIL DAN PEMBAHASAN}

\section{Formulasi Awal Prinsip Ketidakpastian Heisenberg}

Prinsip ketidakpastian Heisenberg menyatakan bahwa "jika pengukuran momentum partikel pada arah sumbu-x dapat dilakukan dengan ketidakpastian $\Delta p_{x}$, maka pengukuran posisi pada sumbu-x pada saat yang sama tidak dapat mempunyai ketelitian lebih besar dari $\Delta x=\frac{\hbar}{2 p_{x}}$.

Nilai rata-rata suatu operator misalnya operator $\hat{A}$ dinyatakan oleh persamaan:

$\Delta A=\langle A-$

$\langle A\rangle\rangle$.

$\Delta A=\int_{-\infty}^{\infty} \Psi^{*}(A-\langle A\rangle) \Psi d x$

$\Delta A=\int_{-\infty}^{\infty} \Psi^{*} A \Psi d x-\langle A\rangle \int_{-\infty}^{\infty} \Psi^{*} \Psi d x$

$\Delta A=\langle A\rangle-\langle A\rangle$

$\Delta A=0$

Demikian juga untuk operator $\hat{B}$, sehingga:

$\Delta A \Delta B=0$

Untuk itu ditinjau nilai akar kuadrat rata-rata (root mean square/RMS) dari operator $\hat{A}$ dan $\hat{B}$, yaitu:

$\Delta A \equiv \sqrt{\left\langle(A-\langle A\rangle)^{2}\right\rangle}$

$(\Delta A)^{2} \equiv\left\langle(A-\langle A\rangle)^{2}\right\rangle$

$(\Delta A)^{2} \equiv\left\langle\tilde{A}^{2}\right\rangle$

Untuk operator $\hat{B}$,

$(\Delta B)^{2} \equiv\left\langle\widetilde{B}^{2}\right\rangle$

Sehingga diperoleh hubungan,

$(\Delta A)^{2}(\Delta B)^{2}=\left\langle\tilde{A}^{2}\right\rangle\left\langle\tilde{B}^{2}\right\rangle$

$(\Delta A)^{2}(\Delta B)^{2}=$

$\left(\int_{-\infty}^{\infty} f^{*} \tilde{A}^{2} f d x\right)\left(\int_{-\infty}^{\infty} g^{*} \tilde{B}^{2} g d x\right)$

Melalui prinsip pertidaksamaan Schwarz yaitu: 
$\left(\int|F|^{2} d x\right)\left(\int|G|^{2} d x\right) \geq\left|\int F^{*} G d x\right|^{2}$

maka akan diperoleh nilai ketidakpastian operator $\hat{A}$ dan $\hat{B}$,

$(\Delta A)^{2}(\Delta B)^{2} \equiv\left\langle\tilde{A}^{2}\right\rangle\left\langle\tilde{B}^{2}\right\rangle$

$(\Delta A)^{2}(\Delta B)^{2} \geq\left|\left\langle\frac{\tilde{A} \tilde{B}+\tilde{B} \tilde{A}}{2}+\frac{\tilde{A} \tilde{B}-\tilde{B} \tilde{A}}{2}\right\rangle\right|^{2}$

$(\Delta A)^{2}(\Delta B)^{2} \geq\left|\left\langle\frac{\tilde{A} \tilde{B}-\tilde{B} \tilde{A}}{2}\right\rangle\right|^{2}$

$(\Delta A)^{2}(\Delta B)^{2} \geq\left|\frac{1}{2}\langle[\tilde{A}, \tilde{B}]\rangle\right|^{2}$

$\Delta A \Delta B \geq \frac{1}{2}|\langle[\tilde{A}, \tilde{B}]\rangle|$

Nilai ketidakpastian operator $\hat{A}$ dan $\hat{B}$ ditentukan oleh hubungan komutasi antara keduanya yang diukur pada waktu yang sama. Sebagai contoh, nilai ketidakpastian antara operator posisi dan momentum sebagai berikut:

$\Delta x \Delta p \geq \frac{1}{2}|\langle[\tilde{x}, \tilde{p}]\rangle|$

$\Delta x \Delta p \geq \frac{1}{2}|\langle i \hbar\rangle|$

$\Delta x \Delta p \geq \frac{1}{2}\left|\int_{-\infty}^{\infty} \Psi^{*}(i \hbar) \Psi d x\right|$

$\Delta x \Delta p \geq \frac{1}{2}|i \hbar|$

$\Delta x \Delta p \geq \frac{\hbar}{2}$

Ketidakpastian Heinsenberg muncul dari sifat alamiah objek mikroskopis yang mempunyai sifat dualisme gelombang-partikel. Objek mikroskopis dapat menyebar ke seluruh ruang dan jika kita ingin melakukan pengukuran terhadap posisi, momentum, dan besaran-besaran fisis lainnya maka harus merusak sistem.

\section{Perkembangan Pengukuran Kuantum}

Ozawa, 2003 mengajukan revisi terhadap prinsip ketidakpastian Heisenberg. Adapun faktor yang mendasari pengajuan revisi tersebut adalah pertimbangan Ozawa bahwa sebelum dilakukan pengukuran pada sistem kuantum, sudah terdapat suatu ketidakpastian posisi dan momentum pada sistem kuantum tersebut (Rozeema, 2012).
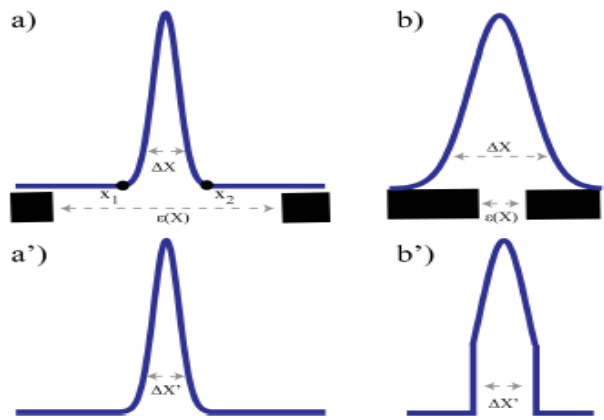

diukur dengan ketelititan $\epsilon(x)$ dengan cara melewatkan elektron melalui celah. a) jika celah lebih lebar daripada fungsi gelombang elektron, $\Delta x<\epsilon(x)$. Sehingga fungsi gelombang elektron tidak terganggu dalam proses pengukuran (yang ditunjukkan oleh gambar a'). b) jika lebar celah lebih kecil daripada fungsi gelombang elektron, $\Delta x>$ $\epsilon(x)$ maka fungsi gelombang elektron akan terganggu dan pada saat proses pengukuran $\Delta x \approx$ $\epsilon(x)$ (Rozeema dkk, 2012).

Gambar 1 mengilustrasikan proses pengukuran posisi elektron dengan melewatkan partikel pada celah. Jika $\Delta x<\epsilon(x)$ dan proses pengukuran berhasil, maka fungsi gelombang partikel tidak pernah menyentuh celah dan dapat lewat tanpa terganggu. Berdasarkan hal tersebut, dapat dilakukan pengukuran dengan $\eta(p)=0$, dan dengan ketelitian pengukuran posisi yang tak terhingga, sehingga berdasarkan prinsip ketidakpastian Heisenberg $\epsilon(x) \eta(p)=0$.

\section{Modifikasi Prinsip Ketidakpastian Heisenberg}

Masanao Ozawa pada tahun 2003 mengajukan revisi terhadap prinsip ketidakpastian Heisenberg. Adapun faktor yang mendasari pengajuan revisi tersebut adalah pertimbangan Ozawa bahwa sebelum dilakukan pengukuran pada sistem kuantum, sudah terdapat suatu ketidakpastian posisi dan momentum pada sistem kuantum tersebut (Rozeema, 2012).

Modifikasi prinsip ketidakpastian Heisenberg diperoleh dengan cara melakukan peninjauan terhadap standar deviasi posisi $\sigma(x)$ dan standar deviasi momentum $\sigma(p)$ dari operator kesalahan pengukuran posisi dan operator gangguan pada momentum (Ozawa, 2005).

Operator kesalahan (error) didefinisikan oleh:

$N(x)=x(\Delta t)-x(0)$ 
$x(\Delta t)=N(x)+x(0)$

Operator gangguan (disturbance) didefinisikan oleh:

$D(p)=p(\Delta t)-p(0)$

$P(\Delta t)=D(p)+p(0)$

Hubungan komutasi antara operator kesalahan dengan operator gangguan dinyatakan oleh:

$[N(x), D(p)]+[N(x), p(0)]+$

$[x(0), D(p)]=-(i \hbar)$,

Substitusi modulus rata-rata dari kedua sisi dan penerapan ketidaksamaan segitiga akan menghasilkan persamaan berikut:

$|\langle[N(x), D(p)]\rangle|+|\langle[N(x), p(0)]\rangle|+$ $|\langle[x(0), D(p)]\rangle| \geq \hbar$

Akar rata-rata kuadrat dari operator kesalahan dinyatakan oleh:

$\epsilon(x)=\left\langle N(x)^{2}\right\rangle^{1 / 2}$

Persamaan (30) merupakan definisi besaran kesalahan menurut Ozawa. Besaran kesalahan yang muncul dalam proses pengukuran akan selalu lebih besar atau sama dengan standar deviasi dari besaran itu sendiri.

$\epsilon(x) \geq \sigma(x)$

Hubungan operator kesalahan dengan operator posisi dinyatakan oleh:

$\epsilon(x)=$

$2\left\langle\hat{x}^{2}\right\rangle^{1 / 2}$

Akar rata-rata kuadrat (root mean square) untuk gangguan (disturbance) pada momentum adalah,

$\eta(p)=$

$\left\langle D(p)^{2}\right\rangle^{1 / 2}$

Persamaan (33) merupakan definisi besaran gangguan menurut Ozawa. Besaran gangguan yang muncul dalam proses pengukuran akan selalu lebih besar atau sama dengan standar deviasi dari besaran itu sendiri. $\eta(p) \geq$

$\sigma(p)$

Hubungan operator kesalahan dengan operator posisi dinyatakan oleh:

$\eta(p)=$

$2\left\langle\hat{p}^{2}\right\rangle^{1 / 2}$

Berdasarkan persamaan (34) dan (35), diperoleh persamaan:

$\epsilon(x) \eta(p) \geq$

$\Delta N(x) \Delta D(p)$,

berdasarkan persamaan Heisenberg-Robertson, yaitu:

$\triangle A \Delta B \geq$

$\frac{1}{2}|\langle[A, B]\rangle|$

Maka diperoleh persamaan,

$\Delta N(x) \Delta D(p) \geq \frac{1}{2}|\langle[N(x), D(p)]\rangle|$,

$\Delta N(x) \Delta p(0) \geq \frac{1}{2}|\langle[N(x), p(0)]\rangle|$

$\Delta x(0) \Delta D(p) \geq \frac{1}{2}|\langle[x(0), D(p)]\rangle|$

Substitusikan persamaan (38), (39), dan (40) ke persamaan (29), akan menghasilkan persamaan:

$$
2 \Delta N(x) \Delta D(p)+2 \Delta N(x) \Delta p(0)+
$$$$
2 \Delta x(0) \Delta D(p) \geq \hbar
$$

$\epsilon(x) \eta(p)+\epsilon(x) \Delta p(0)+\Delta x(0) \eta(p) \geq$

$\frac{1}{2} \hbar$

$\epsilon(x) \eta(p)+\epsilon(x) \sigma(p)+\sigma(x) \eta(p) \geq$

$\frac{\hbar}{2}$.

Persamaan (43) merupakan revisi persamaan ketidakpastian Heisenberg yang diajukan oleh Ozawa.

\section{KESIMPULAN DAN SARAN}


Berdasarkan kajian yang telah dilakukan peneliti, terdapat peluang modifikasi formulasi prinsip ketidakpastian pada teori fisika kuantum disebabkan semakin canggihnya instrument pengukuran kuantum yang ada di abad 21. Adapun peluang modifikasi prinsip ketidakpastian salah satunya dikemukakan oleh Ozawa dengan memasukkan faktor observabel tambahan yang dapat muncul pada saat pengukuran berlangsung yaitu observabel kesalahan (error) yang dinyatakan oleh $\epsilon(x)$ dan observabel gangguan (disturbance) yang dinyatakan oleh $\eta(p)$.

\section{DAFTAR PUSTAKA}

Griffiths, D. J., \& Schroeter, D. F. 2018. Introduction to quantum mechanics. Cambridge University Press.

Heisenberg, W. Uber den anschaulichen Inhalt der quan- " tentheoretischen Kinematik und Mechanik. Z. Phys. 43, 172-198 (1927); The physical content of quantum kinematics and mechanics (Engl. Trans.), in Quantum Theory and Measurement (eds Wheeler, J. A. \& Zurek, W. H.) (Princeton Univ. Press, Princeton, 1983).

Ozawa, M. 2003. Universally valid reformulation of the Heisenberg uncertainty principle on noise and disturbance in measurement. Physical Review A, 67(4), 042105.

Ozawa, M. 2005. Universal uncertainty principle in the measurement operator formalism. Journal of Optics B: Quantum and Semiclassical Optics, 7(12), S672.

Pebralia, J., \& Anggun, S. P. (2019). Pemanfaatan Suling Diatonik Untuk Menghitung
Frekuensi Dan Cepat Rambat Bunyi Di Udara Menggunakan Software Audacity. Jurnal Inovasi Pendidikan, 9(2), 49-56.

Pebralia, J., Suroso, A., \& Zen, F. P. (2019, January). Investigating Starobinsky's Inflation Model Using Arnowitt-DeserMisner (ADM) Formalism for Scalar Perturbation in The Cosmic Inflation Epoch. In Journal of Physics: Conference Series (Vol. 1127, No. 1, p. 012009). IOP Publishing.

Putu, Y. N. N., \& Pebralia, J. (2015). Studi Penerapan Sensor MLX90614 Sebagai Pengukur Suhu Tinggi secara Non-kontak Berbasis Arduino dan Labview. Prosiding Simposium Nasional Inovasi dan Pembelajaran Sains.

Rozema, L. A., Darabi, A., Mahler, D. H., Hayat, A., Soudagar, Y., \& Steinberg, A. M. (2012). Violation of Heisenberg's measurement-disturbance relationship by weak measurements. Physical review letters, 109(10), 100404.

Rozema, L. A., Wang, C., Mahler, D. H., Hayat, A., Steinberg, A. M., Sipe, J. E., \& Liscidini, M. 2015. Characterizing an entangled-photon source with classical detectors and measurements. Optica, 2(5), 430-433

Zettili, N. 2001. Quantum mechanics, concepts and application, john wiely \& sons. INC, New York. 